\title{
Zn/MeOH-Mediated Practical and Easy Detritylation of Protected
}

\section{1-Trityltetrazoles}

Cherif Behloul, ${ }^{* a}$ Kenza Bouchelouche, ${ }^{a}$ Yasmine Hadji, ${ }^{a}$ Saadia Benseghir, ${ }^{a}$ David Guijarro, ${ }^{\text {b,c }}$ Carmen Nájera $^{\mathrm{b}, \mathrm{d}}$ and Miguel Yus ${ }^{\mathrm{b}, \mathrm{d}}$

${ }^{a}$ Laboratoire des Produits Naturels d'origine Végétale et de Synthèse Organique, Université des Frères Mentouri-Constantine 25000 (Algérie)

b Departamento de Química Orgánica, Facultad de Ciencias, Universidad de Alicante, Apdo. 99, 03080 Alicante (Spain)

${ }^{c}$ Instituto de Síntesis Orgánica (ISO), Universidad de Alicante, Apdo. 99, 03080 Alicante (Spain)

d Centro de Innovación en Química Avanzada (ORFEO-CINQA), Universidad de Alicante, Apdo. 99, 03080 Alicante (Spain)

Tel/Fax: 21331818862

Email: afiza72@gmail.com

Received: The date will be inserted once the manuscript is accepted.

Dedicated to the memory of Professors Rafael Usón and Tsutomu Katsuki

\begin{abstract}
A practical and low-cost method for the detritylation of 1-titryltetrazoles using zinc and methanol is described. This procedure is versatile and efficient in the deprotection of several protected tetrazoles bearing aliphatic, aromatic and heteroaromatic substituents, as well as some functional groups, without decomposition of the tetrazoles ring.
\end{abstract}

Keywords: Tetrazoles, zinc/methanol, detritylation, reductive cleavage

Zinc has become an important metal in synthetic organic chemistry. ${ }^{1}$ Over 100 years ago zinc metal was found to react with organic bromides halides to generate organozinc compounds, interesting intermediates for carboncarbon forming reactions. ${ }^{2}$ In addition, the combination of zinc and a hydrogen source has been successfully used as a reducing mixture: this behavior is based on the reduction potential of zinc $(-0.763 \mathrm{~V})$ and its ionization potential $(9.39 \mathrm{eV})$. Thus, this combination, in many cases in the presence of a catalytic amount of a transition metal, has been employed for the reduction of carbon-carbon multiple bonds, and carbon-heteroatom multiple and single bonds. ${ }^{3}$ On the other hand, the trityl group (Tr) has been used as a protecting one for NH groups in several synthetic organic chemistry transformations and therefore the corresponding detritylation plays also an important role at the end of the synthesis. ${ }^{4}$ This methodology was successfully applied, for instance, to the synthesis of losartan, an efficient drug in the treatment of patients with high blood pressure problems. ${ }^{5}$ Some reported procedures for the detritylation of $\mathrm{N}-\mathrm{Tr}$ containing systems include, among others: (a) acidic conditions (hydrogen chloride ${ }^{6}$ and trichloro ${ }^{7}$ or trifluoro ${ }^{8}$ acetic acid), (b) palladium-catalyzed hydrogenation (with molecular hydrogen, ${ }^{9}$ ammonium formate, ${ }^{10}$ or polymethylhydrosiloxane ${ }^{11}$ ), (c) alkali metals in solution (sodium/ammonia ${ }^{12}$ or lithium/naphthalene cat. ${ }^{13}$ ), (d) hydroxybenzotriazol derivatives in trifluoroethanol, ${ }^{14}$ and (e) the use of other metals (such as ytterbium ${ }^{15}$ or indium ${ }^{16}$ ).

Continuing with our interest on deprotection methods, ${ }^{13,16,17}$ we report in this paper an efficient, practical and low-cost methodology for the detritylation of $N$-trityltetrazoles with zinc and methanol, using THF as solvent (Scheme 1).<smiles>[R]c1nnnn1C(c1ccccc1)(c1ccccc1)c1ccccc1</smiles>

1

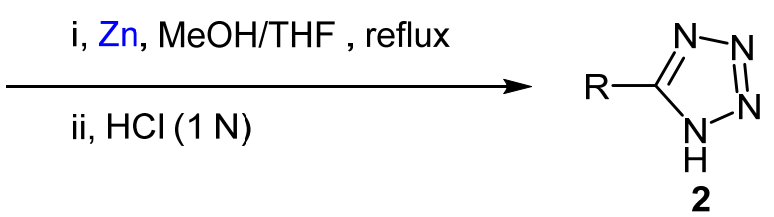

2

\section{Scheme 1}


Starting from 5-phenyl-1-trityltetrazole (1a) we explore several reaction conditions (Table 2): Using zinc at room temperature in methanol, THF or ethanol, as well as a mixture of methanol/THF (2:1) the cleavage failed after $24 \mathrm{~h}$ (Table 1, entries 1-4). However under methanol/THF reflux the expected product 2a was obtained in $92 \%$ yield in only 3 hours (Table 1 , entry 5 ).

Table 1. Assayed Conditions for the Zn-Promoted Cleavage of $1 \mathrm{a}$ for $24 \mathrm{~h}$

\begin{tabular}{lll}
\hline Entry Solvent $\quad \mathrm{T}\left({ }^{\circ} \mathrm{C}\right)$ & Yield $(\%)^{\mathrm{a}}$
\end{tabular}

$\begin{array}{llll}1 & \text { Zn/MeOH } & \text { rt } & 0 \\ 2 & \text { Zn/THF } & \text { rt } & 0 \\ 3 & \text { Zn/EtOH } & \text { rt } & 0 \\ 4 & \text { Zn/MeO/THF } & \text { rt } & 0 \\ 5 & \text { Zn/MeOH/THF } & \text { reflux }^{b} & 92\end{array}$

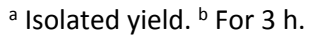

Having the optimal conditions in hand we applied them to differently 5 -substituted 1-trityltetrazoles $\mathbf{1}$ (Table 2). The starting materials 1 were prepared according to our previous reports. ${ }^{13,16}$ When compounds $\mathbf{1}$ were allowed to react with zinc powder (1:1 molar ratio) in a mixture of methanol/THF (2:1) under reflux, and after acidic work-up, the corresponding detritylated tetrazoles 2 were isolated (Scheme 1 and Table 2). The reaction worked properly for 5-aryl (Table 2, entries 1, 2 and 10) and 5-alkyl (Table 2, entries 2 and 9) derivatives, as well as heterocyclic (Table 2, entry 5) or benzylic ones (Table 2, entries 2 and 9). The last case is remarkable because the benzylic group is in some cases sensitive to hydrogenation methods. In addition, a keto group was compatible with the reaction mixture without suffering any alteration (Table 2, entry 8 ). Finally, for compound $\mathbf{1 g}$ it was not necessary to protect the NH group to perform the corresponding detritylation (Table 2, entry 7).

Table 2. Detritylation of Protected Tetrazoles

\begin{tabular}{llll}
\hline Entry Substrate & $t(h)$ & Product & Yield (\%)
\end{tabular}

1<smiles>[3H]n1nnnc1-c1ccccc1</smiles>

2<smiles>Cc1ccc(-c2ccccc2-c2nnnn2I)cc1</smiles>

3<smiles>Cn1nnnc1Cc1ccccc1Cn1nnnc1C(C)(C)C</smiles>

4

5

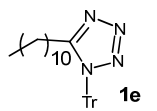

3

19

12

2

11<smiles>[c]1ccc(-c2nnn[nH]2)cc1</smiles>

92<smiles>Cc1ccc(-c2ccccc2-c2nnc[nH]2)cc1</smiles>

91

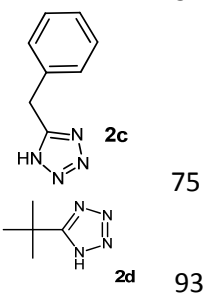

94 


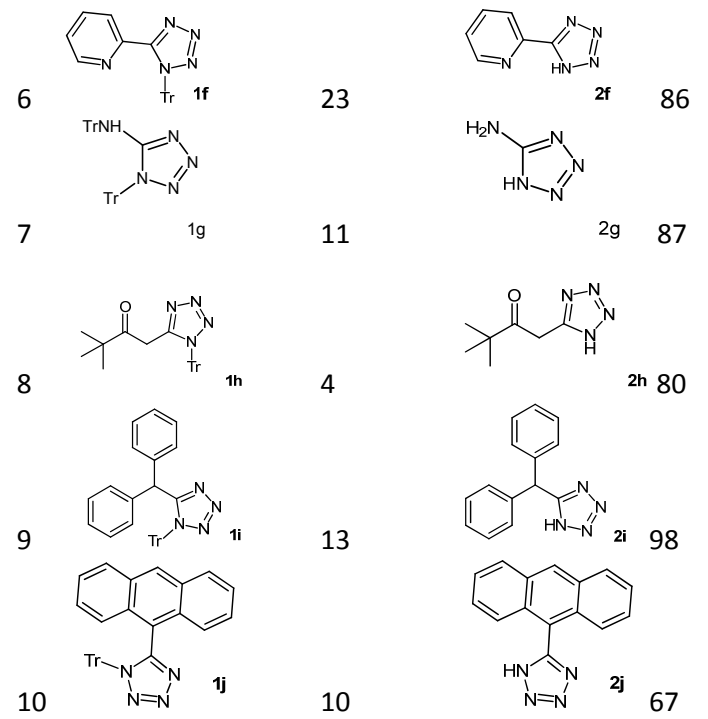

aield of isolated product after purification by column chromatography (basic aluminium oxide, hexane/EtOAc), based on the starting material.

Concerning a possible reaction mechanism, we believe that this is a typical electron-transfer process in which the $\mathrm{C}-\mathrm{N}$ bond is cleaved giving the trityl radical and an anion at the nitrogen. The addition of a second electron to the radical would give the trityl anion, which would be protonated by methanol presented in the reaction medium. The acidic work-up regenerated the expected tetrazoles $\mathbf{2}$ that was very easily separated from triphenylmethane by column chromatography.

In order to compare the methodology described here with the ones using other metals such as lithium or indium, Table 3 shows that in general yields are comparable in the three cases. However, the reaction times are shorter for lithium and longer for indium. It is worthy to note the zinc is the cheapest metal (compared to lithium and indium) and with zinc it is not necessary to work under inert conditions, as it is the case using lithium.

Table 3. Comparison of using $\mathrm{Zn}$, In and $\mathrm{Li}$ in the detritylation of compounds 1

\begin{tabular}{cccccc}
\hline Entry & $\begin{array}{l}\text { Starting } \\
\text { material }\end{array}$ & Product & \multicolumn{3}{c}{ Metal, yield (\%) [time (h)] } \\
& & & & Zn & Li \\
\hline 1 & $\mathbf{1 a}$ & $\mathbf{2 a}$ & $92[3]$ & $93[26]$ & $97[3]$ \\
2 & $\mathbf{1 b}$ & $\mathbf{2 b}$ & $91[19]$ & $96[21]$ & $99[4]$ \\
3 & $\mathbf{1 c}$ & $\mathbf{2 c}$ & $75[12]$ & $80[25.5]$ & $82[3]$ \\
4 & $\mathbf{1 d}$ & $\mathbf{2 d}$ & $93[2]$ & $92[22]$ & $97[4]$ \\
5 & $\mathbf{1 e}$ & $\mathbf{2 e}$ & $94[11]$ & $92[21]$ & $81[3]$ \\
6 & $\mathbf{1 f}$ & $\mathbf{2 f}$ & $86[23]$ & $86[23]$ & $86[4]$ \\
7 & $\mathbf{1 g}$ & $\mathbf{2 g}$ & $87[11]$ & $93[4]$ & $93[2.5]$ \\
8 & $\mathbf{1 h}$ & $\mathbf{2 h}$ & $80[4]$ & $88[20]$ & $80[4]$ \\
9 & $\mathbf{1 i}$ & $\mathbf{2 i}$ & $98[13]$ & $82[23]$ & $84[2]$ \\
10 & $\mathbf{1 j}$ & $\mathbf{2 j}$ & $67[10.5]$ & $77[20]$ & $75[6.5]$ \\
\hline
\end{tabular}

As a conclusion, and considering the low-cost of the metal and the no need of using inert conditions, we believe that zinc is the metal of choice for the detritylation of differently 5 -substituted 1-trityltetrazoles. 
For general information on materials and methods see reference 13b. 1-Trityltetrazoles 1 were prepared and characterized following our reported procedure. ${ }^{13 \mathrm{~b}}$

\section{Reductive Cleavage of 1-Trityltetrazoles 1; General Procedure}

A mixture of the tetrazole $1(0.5 \mathrm{mmol})$ and zinc powder $(22 \mathrm{mg}, 0.5 \mathrm{mmol})$ in methanol $(6 \mathrm{~mL})$ and THF $(3 \mathrm{~mL})$ was refluxed until the starting material was consumed (see Table 2$)$. After cooling at $\mathrm{rt}, 1 \mathrm{M}$ hydrochloric acid $(5 \mathrm{~mL})$ was added and the mixture was extracted with ethyl acetate $(3 \times 15 \mathrm{~mL})$ and the combined organic layer was washed with brine $(5 \mathrm{~mL})$ and dried $\left(\mathrm{Na}_{2} \mathrm{SO}_{4}\right)$. After evaporation of the solvents ( 15 Torr) the resulting residue was purified by column chromatography (basic aluminium oxide, hexane/ethyl acetate) to afford the pure deprotected tetrazoles 2 (purity ( $>95 \%$ by GLC). Compounds 2 were fully characterized by comparison of their spectroscopic data (IR, ${ }^{1} \mathrm{H}$ and ${ }^{13} \mathrm{C}$ NMR) with those of pure compounds 2 obtained previously by us. ${ }^{13 \mathrm{~b}}$

\section{Acknowledgement}

This work was financially supported by the Agence National pour le Développement de la Research en Santé (Algérie) and the Spanish Ministerio de Ciencia e Innovación (CTQ2011-24155, CTQ2011-24165), the Ministerio de Economía y Competitividad (CTQ201343446-P, CTQ2014-51912-REDC, CTQ2014-53695-P), FEDER, the Generalitat Valenciana (PROMETEO 2009/039, PROMETEOII/2014/017), and the University of Alicante. We also thank the Spanish Ministerio de Asuntos Exteriores y de Cooperación (AP/039112/11).

\section{References and Notes}

(1) (a) Erdik, E. Organozinc Reagents in Organic Synthesis; CRC Press: Boca Raton, 1996. (b) Organozinc Reagents: A Practical Approach; Knochel, P.; Jones, P., Eds.; Oxford University Press: Oxford, 1999.

(2) (a) Knochel, P.; Singer, R. D. Chem. Rev. 1993, 93, 2117. (b) Knochel, P.; Almena-Perea, J. J.; Jones, P. Tetrahedron, 1998, 54,8275 .

(3) See, for instance: Schabel, T.; Belger, C.; Plietker, B. Org. Lett. 2013, 15, 2858, and references therein.

(4) (a) Kocienski, P. Protecting Groups, 3rd ed.; G. Thieme: Stuttgart, 2000. (b) Wuts, P. G. M.; Greene, T. W. Protecting Groups in Organic Synthesis, 4th ed.; J. Wiley \& Sons: Hoboken, 2007.

(5) Habashi, J. P.; Judge, D. P.; Holm, T. M.; Cohn, R. D.; Loeys, B. L.; Cooper, T. K.; Myers, L.; Klein, E. C.; Liu, G.; Calvi, C.; Podowski, M.; Neptune, E. R.; Halushka, M. K.; Bedja, D.; Gabrielson, K.; Rifkin, D. B.; Carta, L.; Ramirez, F.; Huso, D. L.; Dietz, H. C. Science 2006, 312 (5770), 117.

(6) Applegate, H. E.; Cimarusti, C. M.; Dolfini, J. E.; Funke, P. T.; Koster, W. H.; Puar, M. S.; Slusarchyk, W. A.; Young, M. G. J. Org. Chem.1979, 44, 811.

(7) Armstrong, R. W.; Moran, E. J. Am. Chem. Soc.1992, 114, 371.

(8) (a) Alsina, J.; Giralt, E.; Albericio, F. Tetrahedron Lett. 1996, 37, 4195. (b) Maltese, M. J. Org. Chem. 2001, 66, 7915. (c) Vedejs, E.; Klapars, A.; Warner, D. L.; Weiss, A. H. J. Org. Chem. 2001, 66, 7542. (d) Vedejs, E.; Naidu, B. N.; Klapars, A.; Wagner, D. L.; Li, V.-s.; Na, Y.; Holm, H. J. Am. Chem. Soc. 2003, 125, 15796.

(9) (a) Zervas, L.; Theodorpoulos, D. J. Am. Chem. Soc. 1956, 78, 1359. (b) Dugave, C.; Menez, A. J. Org. Chem. $1996,61,6067$.

(10) Sharma, S. K.; Songster, M. F.; Colpitts, T. L.; Hegyes, P.; Barany, G.; Castellino, F. J. J. Org. Chem. 1993, $58,4993$.

(11) Chandrasekhar, S.; Babu, B. N.; Reddy, C. R. Tetrahedron Lett. 2003, 44, 2057.

(12) Nesvadba, H.; Roth, H. Monatsh. Chem. 1967, 98, 1432.

(13) (a) Behloul, C.; Guijarro, D.; Yus, M. Synthesis 2004, 1274. (b) Behloul, C.; Guijarro, D.; Yus, M. Synthesis 2014, 46, 2065.

(14) Bodansky, M.; Bednarek, M. A.; Bodansky, A. Int. J. Pept. Protein Res. 1982, 20, 387.

(15) Lu, R. J.; Liu, D.; Giese, R. W. Tetrahedron Lett. 2000, 41, 2817.

(16) Behloul, C.; Bouchemouch, K.; Guijarro, D.; Foubelo, F.; Nájera, C.; Yus, M. Synlett 2015, 26, 2399.

(17) (a) Yus, M.; Behloul, C.; Guijarro, D. Synthesis 2003, 2179. (b) Behloul, C.; Guijarro, D.; Yus, M. Synthesis 2004, 1274. (c) Behloul, C.; Guijarro, D.; Yus, M. Tetrahedron 2005, 61, 6908. (d) Behloul, C.; Guijarro, D.; Yus, M. Tetrahedron 2005, 61, 9319. (e) Behloul, C.; Guijarro, D.; Yus, M. Synthesis 2006, 309. (f) Behloul, C.; Guijarro, D.; Yus, M. Arkivoc 2007, (vii), 41. (g) Behloul, C.; Chouti, A; Guijarro, D.; Nájera, C.; Yus, M. Synthesis 2015, 47, 507. 
Zn/MeOH-Mediated Practical and Easy Detritylation of Protected 1-Trityltetrazoles

Cherif Behloul,* Kenza Bouchelouche, Yasmine Haddji, Saadia Benseghir, David Guijarro, Carmen Nájera and Miguel Yus

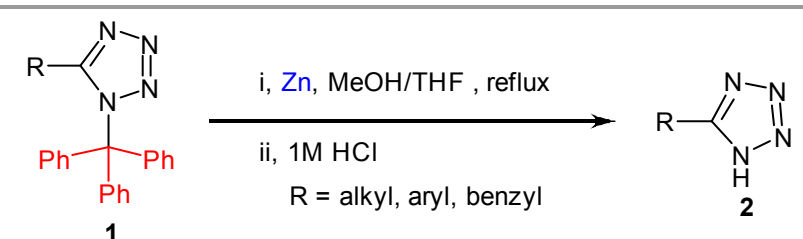

